\title{
TIBIAL DIAPHYSEAL FRACTURES IN ADULTS TREATED BY CLOSED REAMED INTRAMEDULLARY INTERLOCKING NAIL: A FOLLOW-UP STUDY
}

\author{
Vijayashankar M1, Balaji Arumugam²
}

${ }^{1}$ Assistant Professor, Department of Orthopaedics, Tagore Medical College, Chennai.

${ }^{2}$ Professor, Department of Community Medicine, Tagore Medical College, Chennai.

\begin{tabular}{l}
\hline ABSTRACT \\
BACKGROUND \\
Closed Tibial Fractures is one of the commonest injuries among the young and active adults. Intramedullary interlocking nail of these \\
fractures reduces morbidity and provides excellent alignment.
\end{tabular}

\section{OBJECTIVES}

This study was intended with the objective of assessing the efficacy of intramedullary interlocking nail in the treatment of closed tibial fractures.

\section{MATERIALS AND METHODS}

The study was done at a 300 bed tertiary care hospital situated in the heart of Chennai city where more number of orthopaedic cases are admitted. It was done as a hospital-based prospective study during the period of January 2008 to June 2009 , among twenty patients admitted with closed tibial diaphyseal fractures. These patients underwent intramedullary interlocking nailing for fracture fixation in the Department of Orthopaedic Surgery, Southern Railway Headquarters Hospital, Chennai. Results: This study has included 20 patients with closed tibial diaphyseal fractures of which $60 \%$ of study participants showed excellent results, $20 \%$ with good results, fair in $15 \%$, poor in $5 \%$. The complication rate was a little high in this study, which included $10 \%$ malunion, $5 \%$ of infection and $5 \%$ of restriction of ankle and knee movements. Conclusion: Intramedullary interlocking nail is a reliable, versatile and effective treatment for closed tibial diaphyseal fractures as it minimizes the hospital stay and reduces the economic burden and enhances early return to work.

\section{KEYWORDS}

Closed Tibial Fractures, Intramedullary Nailing, Diaphyseal Fractures.

HOW TO CITE THIS ARTICLE: Vijayashankar M, Arumugam B. Tibial diaphyseal fractures in adults treated by closed reamed intramedullary interlocking nail: a follow-up study. J. Evolution Med. Dent. Sci. 2016;5(61):4254-4257, DOI: $10.14260 /$ jemds/2016/971

\section{INTRODUCTION}

Fractures of the tibial shaft are common due to the exposed anatomical location of the tibia. In contrast to the rest of appendicular skeleton, tibial shaft has precarious blood supply due to inadequate muscular enveloped which is a source frequent case of delayed union and non-union. Management of the fractured tibia requires the widest experience, greatest wisdom and the best of clinical judgment in order to choose the most appropriate treatment for a particular pattern of injury Watson and Jones. ${ }^{1}$

"Every fracture is an individual problem and the decision to treat it by internal fixation or indeed conservatively should be based on a realistic assessment of the advantages and the hazards of each method in the circumstances of that particular case. This calls for a high degree of clinical judgment, which is harder to acquire or to impart than technical virtuosity in the operating theatre" Nicoll. ${ }^{2}$

Closed tibial fracture can be treated with various modalities such as conservative management by manipulation and immobilisation using long leg cast, open

Financial or Other, Competing Interest: None.

Submission 20-06-2016, Peer Review 17-07-2016,

Acceptance 23-07-2016, Published 29-07-2016.

Corresponding Author:

Dr. Vijayashankar $M$,

\#No. 9, Sam Villa,

Poompukar Street,

Chitlapakkam,

Chennai-64.

E-mail: vijayashankar.m@gmail.com

DOI: $10.14260 /$ jemds/2016/971 reduction and internal fixation with plates and screws and closed reduction and intramedullary fixation such as Ender Pins, intramedullary nails and interlocking intramedullary nails with or without reaming. The surgeon should be capable of using all these techniques and must weigh advantages and disadvantages of each one and adapt the best possible treatment as per individual patient.

Open reduction and internal fixation with plates and screws has yielded unacceptably high rates of infection. $3,4,5$ This method may be selected with more severe or local injuries associated displaced intra-articular fractures of knee and ankle. The intramedullary nailing, locked or unlocked has become an attractive option since image intensifier has made closed intramedullary nailing possible. Nail is a load sharing device and is stiff to both axial and torsional forces. Closed nailing involves least disturbance of soft tissue, fracture haematoma and natural process of bone healing as compared to other forms of internal fixation.

The locking of intramedullary nails to the major proximal and distal fragments decreases the prevalence of malunion of comminuted fractures. Until recently however all interlocking intramedullary nailing involved reaming, which destroys the endosteal blood supply. ${ }^{6}$ Immobilization in a plaster cast has been used most commonly in the past, but it does not always maintain the length of the tibia and it leaves the wound relatively inaccessible.

\section{AIMS AND OBJECTIVES}

1. To assess the functional and radiological outcomes of closed tibial diaphyseal fractures treated by interlocking intramedullary nailing. 
2. To analyse the factors that affects the outcomes of this particular surgical technique among adult population.

\section{MATERIAL AND METHODS}

This study was done in the Department of Orthopaedics and causality in Southern Railway Headquarters Hospital, Chennai. I intend to study over a period of 18 months with sequentially selected 20 cases. I intend to study on the patient attending Orthopaedic Outpatient Department and casualty.

\section{Inclusion Criteria}

1. It includes patients of age between 20-60 years.

2. Both Males and Females.

3. Type of fractures: All closed fractures.

\section{Exclusion Criteria}

1. It excludes patients of age less than 20 years and more than 60 years.

2. Type of fracture

a. Segmental loss of bone.

b. Compound fractures.

c. Diaphyseal fractures extending into ankle and knee joint.

d. Pathological fractures.

On admission general condition of the patient was assessed with regards to hypovolemia, associated orthopaedic or other systemic injuries and resuscitative measures taken accordingly. All patients received analgesics in the form of IM injections, tetanus toxoid intramuscularly and antibiotics intravenously. A thorough clinical examination was performed including detailed history relating to age, sex, occupation, mode of injury, past and associated medical illness and the limb was immobilized in the form of above knee Plaster of Paris posterior slab limb elevation over a pillow was given in all the patients. Routine investigations were done for all patients. All patients were evaluated clinically and radiographically to assess for any injuries. X-ray was taken in two planes, anteroposterior view and lateral view, and importance is given and other serious injuries like head injuries.

Patients were operated as early as possible once the general condition of the patient was stable and was fit for surgery. Preoperatively, the length of the nail is calculated by subtracting 3 to $4 \mathrm{~cm}$ from measurement taken from the knee joint line to tip of the medial malleolus clinically and medullary canal is measured at the isthmus on X-rays. Accordingly, a stock of interlocking nails $2 \mathrm{~cm}$ above and below the measured length and $1 \mathrm{~mm}$ above and below the required diameter were always kept. We have used solid AO tibial nails in our cases.

\section{Pre-Operative Preparation of Patients}

- $\quad$ Patients were kept NBM for 8-10 hours before surgery.

- IV fluids per the need were given.

- Adequate amount of compatible blood if needed was arranged.

- $\quad$ Preparation of whole extremity, private parts and back was done.

- Written and informed consent was taken.

- Proctoclysis enema HS.

- Tranquilizers HS.

- IV antibiotics half an hour before surgery.

\section{Surgical Technique}

Patients were operated under spinal/general anaesthesia. Patient is placed in supine position over a radiolucent operating table. The injured leg is positioned freely with knee flexed $90^{\circ}$ over the edge of operating table to relax the gastroc soleus muscle (Fig. 2) and allow traction by gravity. The uninjured leg is placed in abduction, flexion and external rotation to ensure free movements of the image intensifier from AP to lateral plane. The table is adjusted to a comfortable operating height.

Pneumatic tourniquet was used in all patients. The affected limb is thoroughly scrubbed from mid-thigh to foot with Betadine scrub and Savlon. Then limb is painted with betadine solution from mid-thigh to foot. Rest of the body and other limb is properly draped with sterile drapes. Sterile gloves are applied to the foot and sterile-drape over the leg from knee joint to ankle.

\section{Post-Operative Care Immediate}

- NBM 4-6 hours post-operatively.

- IV fluids/blood transfusions.

- IV antibiotics.

- IM analgesics.

- Tranquilizers HS.

- Limb elevation over pillows.

- Watch for active bleeding.

- Active toe movements.

- $\quad$ TPR/BP chart every hourly.

- Input/output chart.

- $\quad$ Check X-ray of the operated tibia (Full length) including knee and ankle joints in both AP and lateral view.

Postoperatively, the limb elevation was given over pillows. IV antibiotics is given for 5 days postoperatively. Culture from the wound if necessary sent. Switch over the oral antibiotics is done on the $5^{\text {th }}$ postoperative day. Analgesics if required given. Active knee, ankle and toe mobilization started after overcome from anaesthesia. Patient was allowed non-weight bearing crutch walking/walker on next postoperative day if associated injuries permits, general condition and tolerance of patient. Skin sutures were removed on $10^{\text {th }}$ to $12^{\text {th }}$ postoperative day. Depending upon the culture report and wound condition, antibiotics are stopped/continued. Partial weight bearing crutch walking/walker commenced depending upon the type of fracture, rigidity of the fixation and associated injuries.

\section{Data Collection Technique}

Each patient is individually assessed clinically and radiographically according to the proforma. The demographic data was collected by detailed interview and thorough history and clinical examination. X-rays included anteroposterior and lateral views of affected leg with ankle and knee joint. Postoperatively, X-rays were taken on $1^{\text {st }}$ post-operative day and repeated on every follow-up on $4^{\text {th }}$ week, $8^{\text {th }}$ week, $16^{\text {th }}$ week and $20^{\text {th }}$ week and assessed for evidence of radiological union/angular deformity. The range of motion of knee and ankle joint was assessed with goniometer and the muscle wasting of gastroc-soleus with standard inch tape. All the data were entered in the protocol proforma based on Klemm and Borner criteria which constitutes of ankle and knee range of motion, wasting of gastroc-soleus and malunion. 


\section{Functional Results}

Detailed analysis of function of the patient was done on the basis of the following criteria by Klemm and Borner.7 1986.

\begin{tabular}{|c|c|c|c|}
\hline Excellent & Good & Fair & Poor \\
\hline & Slight Loss of & Moderate $\left(25^{\circ}\right)$ & Marked Loss of \\
Full Knee and & Knee and & Loss of Knee & Knee or Ankle \\
Ankle Motion. & Ankle Motion & (or) Ankle & Motion ( $\left.>25^{\circ}\right)$ \\
No Muscle & $\left(<25^{\circ}\right)$ & Motion & Marked Muscle \\
Atrophy & Less than 20 & More than 2 cm & Atrophy \\
Normal & mm of Muscle & of Muscle & Angular \\
Radiographic & Atrophy & atrophy & Deformities \\
Alignment & Angular & Angular & $\left(>10^{\circ}\right)$ \\
& Deformity & Deformities & \\
& $\left(<5^{\circ}\right)$ & $\left(5-10^{\circ}\right)$ & \\
& \multicolumn{3}{|c}{} \\
\hline
\end{tabular}

\section{Data Analysis}

All categorised demographical data will be presented as frequencies and percentages. The clinical and radiological outcome of treatment, which is assessed as per Klemm and Borner criteria is measured in terms of percentage and in different categories such as Excellent, Good, Fair and Poor.

\section{RESULTS}

The present study includes 20 closed fractures of the tibial shaft surgically treated with closed interlocking intramedullary nailing from January 2008 to June 2009 in the Department of Orthopaedics at Southern Railway Headquarters Hospital, Chennai. The patient have followed up for at least 812 months. All these patients were available for follow-up. Mean age of the study population was 37.5 years of which majority were less than 45 years of age, $80 \%$ were males, $65 \%$ sustained injury on the right leg, $80 \%$ of the fractures were middle and distal one-third location and $65 \%$ had associated fibula fracture. About $70 \%$ of the study participants showed union in 20 weeks, $25 \%$ united around 16 weeks. Complication rate was $15 \%$, of which $5 \%$ was due to infections remaining, $10 \%$ is due to deformity. The overall outcome of the surgery was $60 \%$ excellent (Fig. 2), 20\% good, 15\% fair and 5\% poor results of the surgery (Fig. 1).

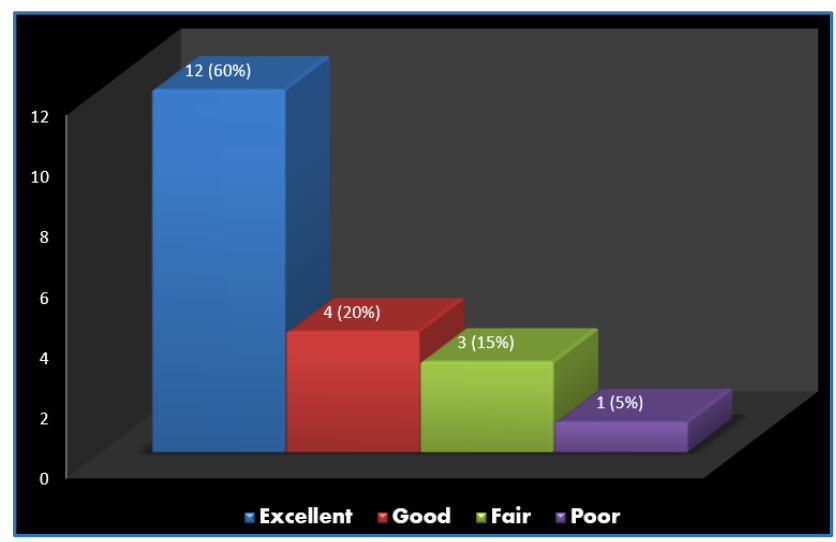

Fig. 1: Showing the Outcome of the IM Nailing Procedure among the Study Participants

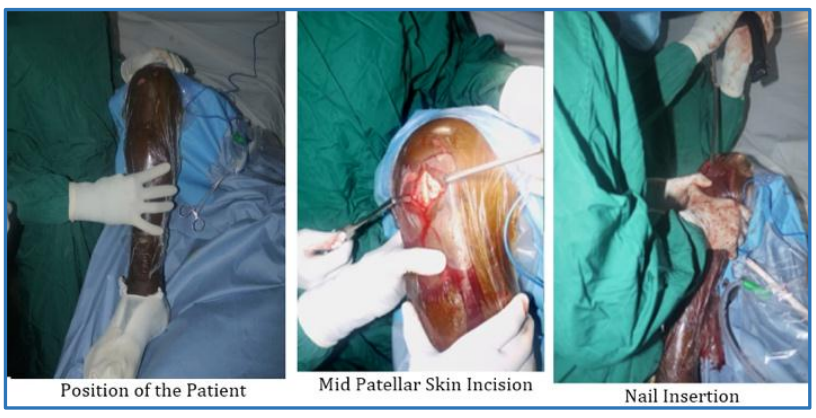

Fig. 2: Surgical Technique Adapted in the Study showing Position, Incision and Nail Insertion

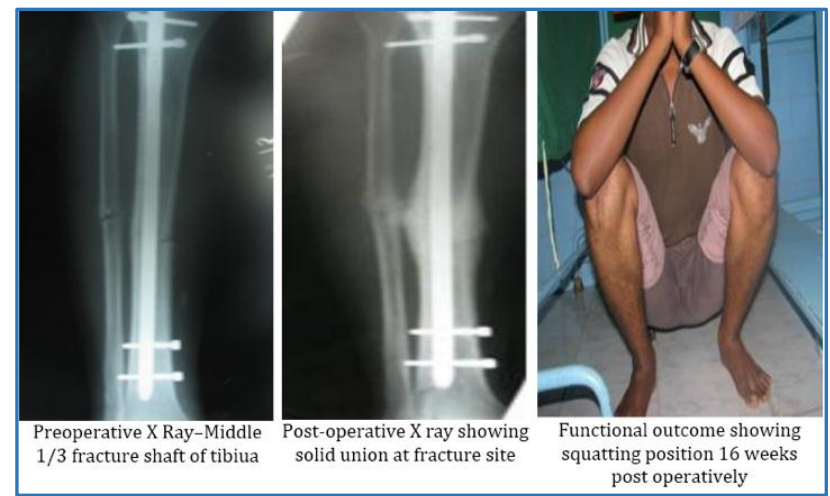

Fig. 3: Preoperative and Post-Operative X-Rays and Squatting Position

\section{DISCUSSION}

A detailed study of the literature of various studies done previously in the same tibial diaphyseal fractures revealed the following observations in terms of various factors as discussed below in separate headings.

\section{Age and Sex Distribution}

Our study showed average age of 37.5 years with range of 2135 years and male predominance showing 15 male and 5 female patients, which is fairly comparable to Whittle et al ${ }^{8}$ showing average age of 34 years with 34 male and 13 female patients, similarly the Singer and Kellam et al ${ }^{9}$ had also showed average age of 36 years with 30 male and 11 female patients. In yet another by Duwelius et al ${ }^{10}$ showing 34 males and 13 females further confirming the male predilection towards fracture occurrence.

\section{Union of Fractures and Complications}

Our study showed the fractures united in 18.4 weeks that was fairly comparable with the series of Blachut et $\mathrm{al}^{11}$ and an infection rate of $5 \%$ which is slightly higher and a nil non-union rate which is better than the Blachut et al, which has $2 \%$ but the malunion rate is higher than Blachut et al, which is $4 \%$. At the same time, the Bone et $\mathrm{al}^{12}$ has comparable Figures with our study in terms of union and better result in terms of malunion which is $2 \%$, but the non-union rate of $2 \%$ shows better result in our study.

The Court-Brown et $\mathrm{al}^{13}$ showed an overall excellent union time of 15.4 weeks, which is better than our study and the nil non-union rate which is in par with our study and at the same time both the malunion and infection rate is nil, which concludes it has better result than our study. 


\section{Nature of Violence}

Majority of the cases sustained fractures from road traffic accidents. Six patients who sustained fracture after a fall and two patients sustained fracture due to assault. Among RTA, motor vehicle accidents 10 cases (50\%) was most common mode of injury in present study. In spite of patient age and gender variability, this study of 20 patients with tibial fractures has given fairly better results.

\section{CONCLUSION}

Our study has shown that the overall functional and clinical outcome of closed reamed Interlocking intramedullary nailing in diaphyseal fractures of tibia was excellent, which may be due to early mobilization with minimal blood loss and risk of infection, strict adherence to technical principles which promoted early union and reduced morbidity.

\section{REFERENCES}

1. Watson-Jones. Injuries of the leg. In: Watson-Jones fractures and joint injuries. Wilson $\mathrm{JN}$, ed. $6^{\text {th }}$ edn. Chapter-32, B.I. New Delhi, Churchill Living stones 1998:pp 1071.

2. Nicoll EA. Fractures of the tibial shaft. A survey of 705 cases. J Bone Joint Surg BR 1964;46:373-87.

3. Bach AW, Hansen ST. Plates versus external fixation in severe open tibia shaft fractures: a randomized trial. Clin Orthop 1989;241:89-94.

4. Ruedi T, Webb JK, Allgower M. Experience with the dynamic compression plate (DCP) in 418 recent fractures of tibial shaft. Injury 1976;7(4):252-7.
5. Smith JE. Results of early and delayed internal fixation for tibial shaft fractures. A review of 470 fractures. J Bone Joint Surg Br 1974;56B(3):469-77.

6. Rhinelander FW. Tibial blood supply in relation to fracture healing. Clin Orthop Relat Res 1974;105:34-81.

7. Klemm KW, Borner M. Interlocking nailing of complex fractures of the femur and tibia. Clinc Orthop Relat Res 1986;212:89-100.

8. Whittle AP, Russell TA, Taylor JC, et al. Treatment of open fracture of the tibial shaft with the use of interlocking nailing without reaming. J Bone Joint Surg 1992;74(8):1162-71.

9. Singer RW, Kellam JF. Open tibial diaphyseal fractures. Results of undreamed locked intramedullary nailing. Clin Orthop Relat Res 1995;315:114-8.

10. Duwelius PJ, Schmidt AH, Rubinstein RA, et al. Nonreamed interlocked intramedullary tibial nailing. One community's experience. Clin Orthop Relat Res 1995;315:104-13.

11. Blachur PA, O’Brien PJ, Meek RN, et al. Interlocking intramedullary nailing with and without reaming for the treatment of closed fractures of the tibial shaft. J Bone Joint Surg 1997;79(5):640-6.

12. Bone LB, Johnson KD. Treatment of tibial fractures by reaming and intramedullary nailing. J Bone Joint Surg Am 1986;68(6):877-87.

13. Court-Brown CM, Hughes SP. Hughes external fixator in treatment of tibial fractures. J R Soc Med 1985;78(10):830-7. 